\title{
Application of the Taguchi Method to Optimize Graphene Coatings on Copper Nanoparticles Formed Using a Solid Carbon Source
}

\author{
Dahyun Choi ${ }^{1}$, Youngjun Pyo ${ }^{1}$, Seung-Boo Jung ${ }^{2}$, Yongil Kim ${ }^{3}$, Eric H. Yoon ${ }^{4}$ \\ and Caroline Sunyong Lee ${ }^{1, *}$ \\ ${ }^{1}$ Materials engineering, Hanyang University, Ansan-si, Gyeonggi-do, 426-791, Republic of Korea \\ ${ }_{2}^{2}$ School of Advanced Materials Science and Engineering, Sungkyunkwan University, Suwon-si, Gyeonggi-do, 440-746, Republic of Korea \\ ${ }^{3}$ Micro Electronic Packaging Laboratory, Sungkyunkwan University, Suwon-si, Gyeonggi-do, 440-746, Republic of Korea \\ ${ }^{4}$ DAECHANG Co., Ltd., Siheung-si, Gyeonggi-do, 15076, Republic of Korea
}

\begin{abstract}
Graphene has attracted much recent interest as an electronic material due to its large electron mobility. Large-area graphene has been synthesized using chemical vapor deposition (CVD). However, it is difficult to apply this process to grow graphene on nanoparticles (NPs) because of their small radius of curvature, which results in a large defect density. In this work, we used the Taguchi method to optimize the deposition of graphene on nanoparticles. We used polyvinylpyrrolidone (PVP) to coat copper NPs via CVD and optimized the process conditions using a minimal number of experiments. The PVP served as the solid carbon source, forming graphene when heated to $875^{\circ} \mathrm{C}$. To improve the quality of the graphene coatings on the Cu NPs, the following process parameters were varied: gas conditions (ratio of $\mathrm{Ar}$ to $\mathrm{H}_{2}$ ), process time and temperature, the amount of PVP solution, and the molecular weight of PVP. We identified optimal process conditions using only eight experiments. Raman spectroscopy was used to analyze the quality of the graphene coatings by comparing two-dimensional (2D) spectra and $I_{\mathrm{D}} /$ $I_{\mathrm{G}}$ ratios of the different coatings. A decrease in $I_{\mathrm{D}} / I_{\mathrm{G}}$, in combination with sharper Raman bands, is indicative of the thickness and crystal quality of the graphene layer. The quality of the graphene layer was also evaluated using transmission electron microscopy (TEM) and scanning electron microscopy (SEM).

The optimal conditions for the formation of graphene-coated $\mathrm{Cu}$ NPs were: a temperature of $875^{\circ} \mathrm{C}$, a deposition time of 2 minutes, an Ar-to- $\mathrm{H}_{2}$ ratio of 1:1, PVP with a molecular weight of $M_{W}=3,500$ (K-12) during the polyol process, and a 50-wt.\% PVP solution with $M_{W}=$ 45,000 (K-30). Using the Taguchi method, we identified trends relating defect density versus process conditions and successfully obtained a graphene coating with a minimal defect density. [doi:10.2320/matertrans.M2016011]
\end{abstract}

(Received January 12, 2016; Accepted April 13, 2016; Published May 13, 2016)

Keywords: copper nanoparticles, graphene, polyvinylpyrrolidone (PVP), solid carbon source, Taguchi method

\section{Introduction}

Conductive nanoinks are suitable for the formation of fine patterns, exhibit good dispersibility in solvents, and have been applied in various fields of electronics. However, the materials used in conductive nanoinks are limited mainly to expensive metals such as $\mathrm{Ag}, \mathrm{Au}, \mathrm{Pt}$ and $\mathrm{Pd}^{1-3)}$. Copper has a large electrical conductivity, and is relatively inexpensive $e^{4,5)}$. Hence, there is significant interest in replacing these noble metals with $\mathrm{Cu}$.

With $\mathrm{Cu}$-based nanoinks, preventing aggregation and oxidation of the nanoparticles (NPs) is important ${ }^{6)}$. There exist various techniques to inhibit the oxidation of copper NPs, including coating them with noble metals ${ }^{7,8)}$, self-assembled monolayers ${ }^{9,10)}$, polymers ${ }^{11)}$, or carbon-based materials ${ }^{12,13)}$. Polyvinlypyrrolidone (PVP) makes a particularly interesting coating for the prevention of copper NP oxidation. However, PVP-coated copper NPs are not readily dispersed in solvents and a dispersant must be added to the nanoink. This makes low-temperature sintering difficult because the presence of the dispersant can result in necking among the copper NPs. The use of carbon-based coating materials can also prevent the oxidation of the $\mathrm{Cu} \mathrm{NPs}^{14}$. However, amorphous carbon is electrically insulating, which is problematic for conductive nanoinks.

For these reasons, graphene is particularly interesting as a coating material for the prevention of $\mathrm{Cu} \mathrm{NP}$ oxidation in conductive nanoinks. Graphene can prevent not only oxida-

*Corresponding author, E-mail: sunyonglee@ hanyang.ac.kr tion from air ${ }^{14,15)}$, but also its large electrical and thermal conductivities make it suitable for applications in electronic devices ${ }^{16,17)}$. However, graphene is prone to structural defects due to the adsorption of contaminants onto its surface and breaking of the hexagonal bonding structure, which reduces the electrical conductivity, especially with very thin layers of graphene $^{17-20)}$.

A source of carbon is required to form graphene. Commonly used sources include $\mathrm{CH}_{4}$ gas, which forms graphene via chemical vapor deposition (CVD), and enables large-area depositions with high quality ${ }^{21-24)}$. However, with a gaseous carbon source, the efficiency of the reaction is low and there is a risk of explosion. A gas source can also be used to form graphene on $\mathrm{Cu}$ NPs, but tends to accelerate necking among the NPs ${ }^{25)}$. The purpose of this study was to demonstrate a PVP coating layer as a solid carbon source. It has been shown that it is possible to convert some of the polymer into graphene at $900^{\circ} \mathrm{C}^{25-27)}$, which is suitable for the CVD deposition of graphene ${ }^{25)}$.

Raman spectroscopy can be used to confirm the presence of graphene. The Raman spectra of graphene exhibit specific peaks corresponding to the $\mathrm{D}, \mathrm{G}$ and $2 \mathrm{D}$ bands. These are related to the A1' vibrational mode, which is indicative of the symmetry of the hexagonal lattice. A peak for the D band appears when the symmetry of this mode is broken by structural defects. In other words, the presence of a D peak indicates that the graphene is defect rich or that there is structural disorder ${ }^{28)}$. The $\mathrm{G}$ peak corresponds to an optical phonon mode, whereby adjacent carbon atoms vibrate in opposite directions. The $\mathrm{E}_{2 \mathrm{~g}}$ vibrational mode is also related to symme- 
try and this peak is associated with vibrations of $\mathrm{sp}^{2}$-hybridized bonds, commonly found in carbon-based materials ${ }^{29}$. The $2 \mathrm{D}$ band is related to secondary Raman scattering. With single- or double-layer graphene, the $2 \mathrm{D}$ band peak is both intense and sharp. If the graphene has three or more layers, this peak broadens because of overlap between the lay$\mathrm{ers}^{28,30,31)}$. For these reasons, the intensity ratio $I_{\mathrm{D}} / I_{\mathrm{G}}$ corresponds to the defect density, and the ratio $I_{2 \mathrm{D}} / I_{\mathrm{G}}$ is indicative of the number of layers.

Taguchi methods are used to identify trends using a minimum number of experiments where there are many variables in a given experiment. Taguchi methods have been applied in several research areas as a means of optimizing conditions. A Taguchi method is characterized by five stages: 1) problem identification, 2) decisions about the control and signal factors, levels and objectives, 3 ) design of experiment, 4) experimental implementation, and 5) analysis of the results ${ }^{32)}$. First, an understanding of the variables is required to identify an appropriate control factor. In general, the variables should be adjusted as factors that are controlled during the experiments. A signal factor was not considered here as this is a non-adjustable variable. After a variable had been selected in step 2, we established the number of levels as 2-4 per variable. It is also important to select appropriate experimental objectives, and three is common. For a given parameter, the optimum result can be characterized in three ways: either smaller is better, on-target is better, or larger is better. For the first case, where smaller is better, a smaller experimental result represents higher quality ${ }^{33)}$. For the second case, where nominal is better, good results are generally obtained when the result is closer to the target, with minimal variance. For the third case, where the optimal value is larger ${ }^{34)}$, the value improves as it increases. In this manner, the trends used to identify the optimal conditions can be found by sorting the values of the variables and by running additional experiments to confirm predictions.

Here, a PVP coating was layered onto $\mathrm{Cu}$ NPs using a polyol method. The PVP was then used as a solid carbon source and converted to graphene via CVD. We investigated the influence of the quantity and molecular weight of the PVP solution, the atmospheric conditions, the process time, and the process temperature on the quality of the graphene coatings formed on $\mathrm{Cu}$ NPs, while preventing necking of the NPs. The quality of the graphene layers was characterized using transmission electron microscopy (TEM), scanning electron microscopy (SEM), and Raman spectroscopy.

\section{Experimental}

\subsection{CVD coating process}

Copper NPs were synthesized with a diameter of $\sim 100 \mathrm{~nm}$ using a polyol method to form PVP-coated NPs ${ }^{35,36)}$. A diethylene glycol (DEG, Extra pure, 1 L, JUNSEI, Japan) solution was used during the polyol process and was subsequently removed using methanol and centrifugation. The PVP solution was formed using a solution of PVP powder (SHOWA, K-30, Japan) in chloroform (JUNSEI, Japan) and dimethylformamide (DMF) (DAEJUNG, Korea) at a mass ratio of 5:5:1. Finally, PVP solutions, from $30 \mathrm{wt} . \%$ to $50 \mathrm{wt} . \%$, were added into the solution to minimize amount of necking among par-

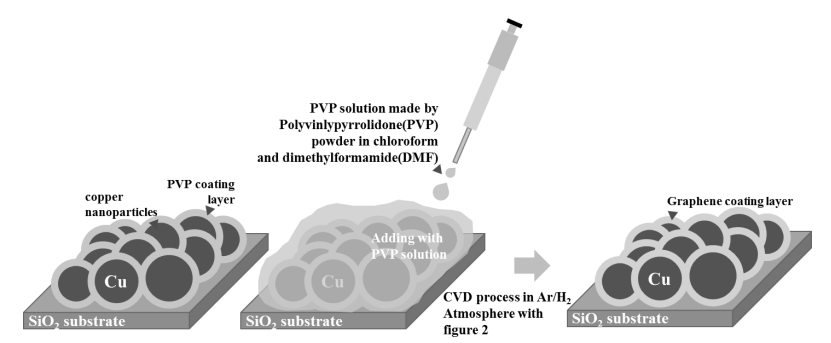

Fig. 1 Schematic diagram of the process used to form graphene coatings on copper nanoparticles.

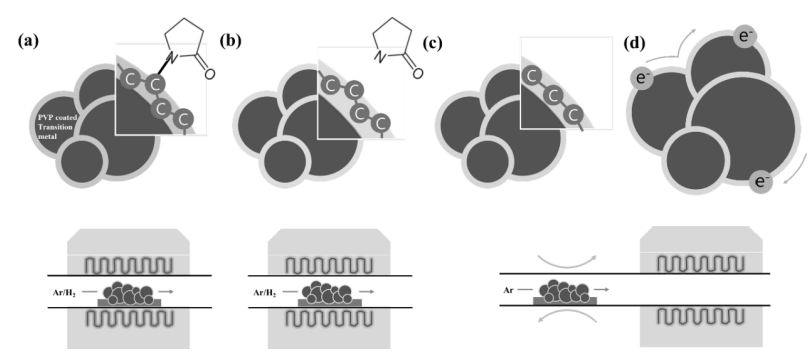

Fig. 2 (a) Schematic diagram of the graphene coating before heating. (b) Formation of an amorphous carbon layer via thermal decomposition of $\mathrm{C}-\mathrm{N}$ bonds. (c) Alignment of carbon chains on the surface of the nanoparticles. (d) The resulting graphene-coated copper nanoparticles.

ticles during the CVD process. The resulting mixture was deposited on $\mathrm{SiO}_{2}$ substrates with planar dimensions of $1.5 \times$ $1.5 \mathrm{~cm}^{2}$, as shown in Fig. 1, and dried in a glove box for 2 hours in an Ar atmosphere. The PVP layer was then converted to graphene via CVD in a quartz chamber. The PVP solution inhibited necking of adjacent copper NPs. The heating rate of the CVD system was $60^{\circ} \mathrm{C} / \mathrm{min}$. The NPs were allowed to cool to room temperature following this heating process. The process temperature, process time, and ratio of $\mathrm{Ar}$ and $\mathrm{H}_{2}$ gases were varied during the CVD process. The concentration and molecular weight of the PVP solution that was coated onto the $\mathrm{Cu}$ NPs, were controlled.

Figure 2 shows the mechanism of graphene formation on $\mathrm{Cu}$ NPs via CVD. When the PVP layer was heated above $850^{\circ} \mathrm{C}$ in $\mathrm{Ar}$ and $\mathrm{H}_{2}$, bonds between nitrogen and the carbon chain of PVP thermally decomposed and the coating layer was transformed into amorphous carbon. The sample was then allowed to cool to room temperature. The amorphous carbon layer aligned and was thereby converted to graphene, as shown in Fig. 2(c).

The resulting coating layers were characterized using TEM (JEM-2100F HR, JEOL) to measure layer thickness. The degree of necking between $\mathrm{Cu}$ NPs was investigated using SEM (S4800, Hitachi). The conversion of the polymer layer to graphene was investigated using Raman spectroscopy (RM 1000, RENISHAW).

\subsection{Design of experiments}

Table 1 lists the variables used in the conversion of the PVP coating to graphene. The ranges of experimental conditions indicated in the table were determined in a preliminary study by Cho. et al. ${ }^{37)}$. Three different gas compositions were used at two different temperatures, times, concentrations of PVP, and molecular weights of PVP. As the number of param- 
eters increased, the number of experiments required to consider each factor increased exponentially. Thus 8 parameters, each of which is evaluated at two levels, would require a time-consuming $2^{8}=256$ experiments. However, the Taguchi method allows for a fractional design that reduces the number of experiments by disregarding interactions among the various factors ${ }^{32)}$. This makes the Taguchi method suitable for investigating trends with many variables.

Argon and hydrogen atmospheres are typically employed in the CVD growth of graphene. The densities of defects, edge dislocations, and wrinkles on the graphene surface increase as the hydrogen fraction decreases ${ }^{38)}$. In our experiments, we varied the process temperature, the quantity of PVP in the solution, and the process time to minimize necking. We also used low-molecular-weight PVP in order to minimize the thickness of the graphene layer.

The gas ratio was varied to minimize the density of structural defects that result from hydrogen gas adsorption onto the surface of graphene. We varied the $\mathrm{Ar}: \mathrm{H}_{2}$ ratio through $1: 1,1: 0.75$, and $1: 0.5$. The total quantity of gas was fixed at $140 \mathrm{sccm}$. PVP can be converted to graphene at temperatures $>850^{\circ} \mathrm{C}^{25}$ ) and we evaluated process temperatures of $875^{\circ} \mathrm{C}$ and $900^{\circ} \mathrm{C}$. The CVD process times were 2 and $3 \mathrm{~min}$, and the concentration of the PVP solution was either 30 or $50 \mathrm{wt} . \%$. The molecular weights of PVP were K-12 $(3,500)$ or K-30 $(45,000)$. Normally, this parameter space would require a total of $\left(2^{5} \cdot 3^{1}\right)=96$ experiments for a full evaluation. However, the Taguchi method enabled us to investigate these parameters using only eight experiments (Table 2).

Table 1 Variables in the Taguchi method.

\begin{tabular}{cccc}
\hline Variable & \multicolumn{3}{c}{ Levels } \\
\hline Gas Ratio of Ar: $\mathbf{H}_{\mathbf{2}}$ & $1: 1$ & $\mathbf{2}$ & $\mathbf{3}$ \\
Temperature $\left({ }^{\circ} \mathrm{C}\right)$ & 875 & $1: 0.75$ & $1: 0.5$ \\
Time $($ min) & 2 & 900 & \\
PVP solution (wt.\%) & 30 & 3 & \\
PVP molecular weight & $3,500(\mathrm{~K}-12)$ & $45,000(\mathrm{~K}-30)$ \\
\hline
\end{tabular}

Table 2 Design of experiments.

\begin{tabular}{cccccc}
\hline & \multicolumn{5}{c}{ Variables } \\
Experiment & $\begin{array}{c}\text { Gas Ratio } \\
\text { of Ar:H2 }\end{array}$ & $\begin{array}{c}\text { Temperature } \\
\left({ }^{\circ} \mathrm{C}\right)\end{array}$ & $\begin{array}{c}\text { Time } \\
\text { (min) }\end{array}$ & $\begin{array}{c}\text { PVP } \\
\text { solution } \\
\text { (wt.\%) }\end{array}$ & $\begin{array}{c}\text { PVP Molecular } \\
\text { weight }\end{array}$ \\
\hline D1 & $1: 1$ & 875 & 2 & 30 & $45,000(\mathrm{~K}-30)$ \\
D2 & $1: 1$ & 875 & 2 & 50 & $45,000(\mathrm{~K}-30)$ \\
D3 & $1: 1$ & 900 & 3 & 30 & $45,000(\mathrm{~K}-30)$ \\
D4 & $1: 0.75$ & 900 & 3 & 30 & $45,000(\mathrm{~K}-30)$ \\
D5 & $1: 0.5$ & 900 & 3 & 30 & $45,000(\mathrm{~K}-30)$ \\
D6 & $1: 0.5$ & 900 & 2 & 30 & $45,000(\mathrm{~K}-30)$ \\
D7 & $1: 0.5$ & 875 & 2 & 30 & $45,000(\mathrm{~K}-30)$ \\
D8 & $1: 1$ & 875 & 2 & 50 & $3,500(\mathrm{~K}-12)$ \\
\hline
\end{tabular}

\section{Results and Discussion}

\subsection{CVD process conditions}

To apply the Taguchi method to our experimental results, we must convert the measured ratios $I_{\mathrm{D}} / I_{\mathrm{G}}$ to signal-to-noise $(\mathrm{S} / \mathrm{N})$ ratios. Quantification of the $\mathrm{S} / \mathrm{N}$ ratio facilitates the simple identification of potential improvements.

Figure 3 shows Raman spectra for the 8 samples listed in Table 2. The D, G, and 2D peaks were observed for all samples. The peak corresponding to the $\mathrm{D}$ band appears due to the curvature of the graphene and structural defects caused by absorption of atoms on the graphene surface. The $\mathrm{Cu}$ NPs used here were spherical, resulting in a high degree of surface curvature and a correspondingly strong $\mathrm{D}$ band peak ${ }^{25)}$. The presence of a $\mathrm{G}$ band peak indicates that all of the samples were carbon-based materials. The ratio $I_{\mathrm{D}} / I_{\mathrm{G}}$ was used as an indirect measure of the defect density in the graphene coating. Table 3 lists the $\mathrm{S} / \mathrm{N}$ ratios obtained from all 8 samples.

The ratio $I_{\mathrm{D}} / I_{\mathrm{G}}$ can be converted to an $\mathrm{S} / \mathrm{N}$ ratio as follows ${ }^{33)}$ :

$$
(S / N)_{\text {smaller-is-better }}=-10 \log _{10}\left[1 / n \sum_{i=1}^{n}\left(Y_{i}^{2}\right)\right]
$$

\subsection{Optimization}

Figure 4 shows the average $\mathrm{S} / \mathrm{N}$ ratio corresponding to the level of each of the variables, as calculated using $I_{\mathrm{D}} / I_{\mathrm{G}}$. Figure 4 shows $I_{\mathrm{D}} / I_{\mathrm{G}}$ for temperatures of $875^{\circ} \mathrm{C}$ and $900^{\circ} \mathrm{C}$. The DOE samples D1, D2, D7, and D8 were processed at $875^{\circ} \mathrm{C}$

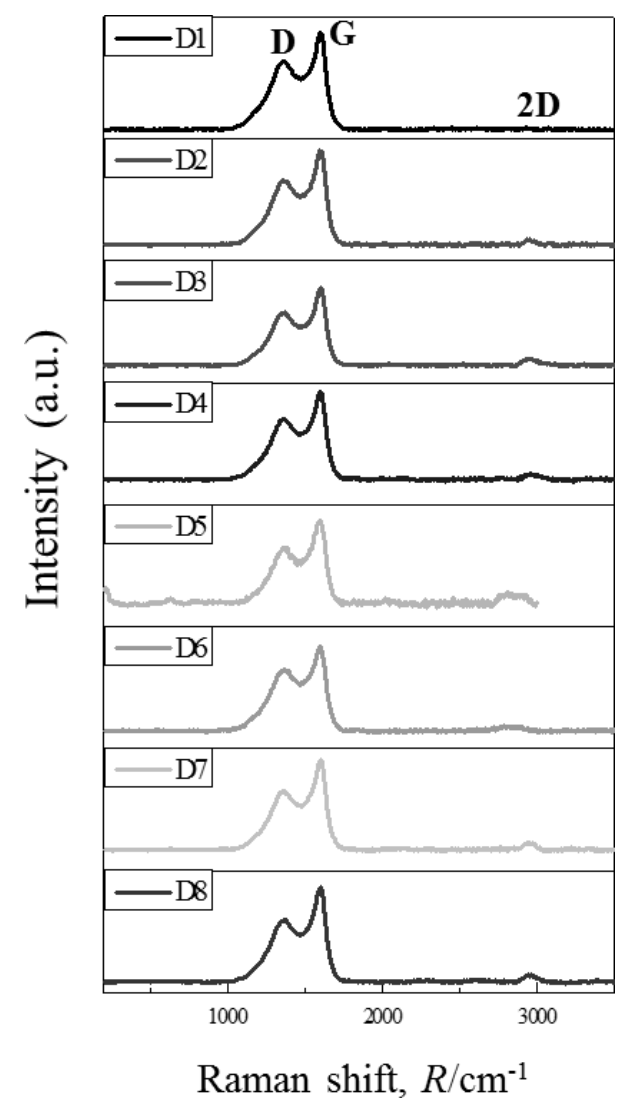

Fig. 3 Raman spectra of samples formed with the process conditions listed in Table 2 . 
Table 3 Signal-to-noise (S/N ratios) calculated from $I_{\mathrm{D}} / I_{\mathrm{G}}$.

\begin{tabular}{ccc}
\hline \multirow{2}{*}{ Experiments } & \multicolumn{2}{c}{$\mathbf{I}_{\mathbf{D}} / \boldsymbol{I}_{\mathbf{G}}$ ratio } \\
\hline D1 & Result & $\mathbf{S} / \mathbf{N}(\mathbf{d B})$ \\
D2 & 0.70 & 3.10 \\
D3 & 0.70 & 3.10 \\
D4 & 0.71 & 3.01 \\
D5 & 0.70 & 3.07 \\
D6 & 0.72 & 2.88 \\
D7 & 0.74 & 2.63 \\
D8 & 0.71 & 3.00 \\
\end{tabular}

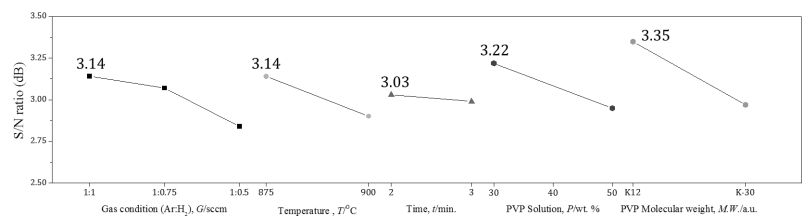

Fig. 4 Signal-to-noise $(\mathrm{S} / \mathrm{N})$ ratios calculated using $I_{\mathrm{D}} / I_{\mathrm{G}}$ for the samples listed in Table 3.

and the corresponding $\mathrm{S} / \mathrm{N}$ ratios were $3.10,3.10,3.00$, and 3.35 , respectively. The mean of these data is 3.14 , as shown in Fig. 4.

The condition resulting in the largest $\mathrm{S} / \mathrm{N}$ ratio for each variable was considered optimal, corresponding to a lower defect density or thinner graphene coating. The minimal defect density was observed under the following process conditions: a gas mixture of Ar: $\mathrm{H}_{2}=1: 1\left(\mathrm{~S} / \mathrm{N}\right.$ ratio of $\left.I_{\mathrm{D}} / I_{\mathrm{G}}=3.14\right)$, a process temperature of $875^{\circ} \mathrm{C}\left(\mathrm{S} / \mathrm{N}\right.$ ratio of $\left.I_{\mathrm{D}} / I_{\mathrm{G}}=3.14\right)$, a processing time of $2 \mathrm{~min}\left(\mathrm{~S} / \mathrm{N}\right.$ ratio of $\left.I_{\mathrm{D}} / I_{\mathrm{G}}=3.03\right)$, a $30 \mathrm{wt} . \%$ PVP solution $\left(\mathrm{S} / \mathrm{N}\right.$ ratio of $\left.I_{\mathrm{D}} / I_{\mathrm{G}}=3.22\right)$ and a molecular weight of PVP of 3,500 (i.e., K-12) (S/N ratio of $I_{\mathrm{D}} /$ $\left.I_{\mathrm{G}}=3.35\right)$, as shown in Fig. 4 .

Figure 5 shows the different influences between the maximum and minimum values of each parameter for both $I_{\mathrm{D}} / I_{\mathrm{G}}$. These data determine the degree of influence of each parameter. The variable with the greatest impact on $I_{\mathrm{D}} / I_{\mathrm{G}}$ was the molecular weight of the PVP. Based on these data, condition A1 exhibited the lowest defect density in graphene coating layers. Therefore, the optimal conditions were as follows: a molecular weight of PVP during the polyol process of $M_{W}=$ 3,500 (K-12) and 30 wt.\% PVP solution with $M_{W}=45,000$ (K-30), a $1: 1 \mathrm{Ar}: \mathrm{H}_{2}$ ratio during $\mathrm{CVD}$, and a process time of $2 \mathrm{~min}$ at $875^{\circ} \mathrm{C}$.

\subsection{Additional experiments in accordance with the amount of PVP solution}

Section 3.2 summarized the optimum conditions for a minimum number of defects in the graphene coating layer (Table 4). To confirm this optimum condition experimentally, additional experiments, such as increasing the wt.\% of PVP solution to minimize the necking in the Cu NPs, were performed to determine whether it could be applied to conductive copper nanoink with a graphene coating on $\mathrm{Cu}$ NPs (Table 5).

Figure 6 shows copper nanoparticles that were coated with a graphene coating layer via a CVD process, based on A1
The degree of influence of the control factors based on $\mathbf{I}_{\mathbf{D}} / \mathbf{I}_{\mathbf{G}}$ ratio.

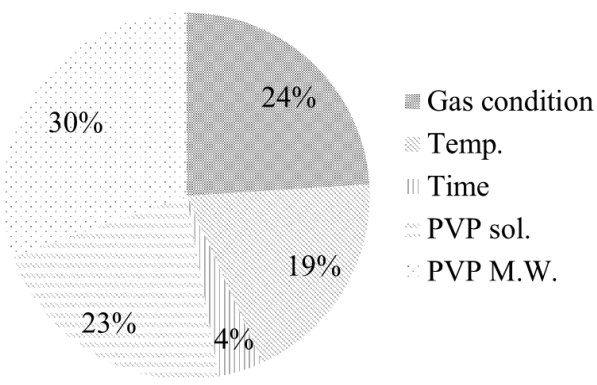

Fig. 5 Degree of influence of the variables, based on $I_{\mathrm{D}} / I_{\mathrm{G}}$ ratio.

Table 4 Optimized conditions based on $\mathrm{S} / \mathrm{N}$ ratios calculated from $I_{\mathrm{D}} / I_{\mathrm{G}}$.

\begin{tabular}{cccccc}
\hline Optimized & \multicolumn{5}{c}{ Variables } \\
condition & $\begin{array}{c}\text { Gas Ratio } \\
\text { of Ar:H }\end{array}$ & $\begin{array}{c}\text { Temperature } \\
\left({ }^{\circ} \mathrm{C}\right)\end{array}$ & $\begin{array}{c}\text { Time } \\
(\text { min) }\end{array}$ & $\begin{array}{c}\text { PVP } \\
\text { solution } \\
(\text { wt. \%) }\end{array}$ & $\begin{array}{c}\text { PVP Molecular } \\
\text { weight }\end{array}$ \\
\hline $\begin{array}{c}\text { (A1) } \\
\text { Smaller } \\
\text { Defect }\end{array}$ & $1: 1$ & 875 & 2 & 30 & $3,500(\mathrm{~K}-12)$ \\
\hline
\end{tabular}

Table 5 Conditions for additional experiments based on $\mathrm{S} / \mathrm{N}$ ratios calculated from $I_{\mathrm{D}} / I_{\mathrm{G}}$.

\begin{tabular}{cccccc}
\hline & & \multicolumn{4}{c}{ Variables } \\
Experiment & $\begin{array}{c}\text { Gas Ratio } \\
\text { of Ar:H } \mathbf{H}_{2}\end{array}$ & $\begin{array}{c}\text { Temperature } \\
\left({ }^{\circ} \mathrm{C}\right)\end{array}$ & $\begin{array}{c}\text { Time } \\
(\mathbf{m i n})\end{array}$ & $\begin{array}{c}\text { PVP } \\
\text { solution } \\
(\mathbf{w t . \%})\end{array}$ & $\begin{array}{c}\text { PVP Molecular } \\
\text { weight }\end{array}$ \\
\hline $\mathbf{A 1}$ & $1: 1$ & 875 & 2 & 30 & $3,500(\mathrm{~K}-12)$ \\
$\mathbf{A 1 - 2}$ & $1: 1$ & 875 & 2 & 40 & $3,500(\mathrm{~K}-12)$ \\
$\mathbf{A 1 - 3 ,} \mathbf{D 8}$ & $1: 1$ & 875 & 2 & 50 & $3,500(\mathrm{~K}-12)$ \\
\hline
\end{tabular}

\begin{tabular}{cc}
\hline \multirow{2}{*}{ Experiments } & $\mathbf{I}_{\mathbf{D}} / \mathbf{I}_{\mathbf{G}}$ ratio \\
& Result \\
\hline $\mathbf{A 1}$ & 0.675 \\
$\mathbf{A 1 - 2}$ & 0.676 \\
$\mathbf{A 1 - 3}(\mathbf{D} 8)$ & 0.680
\end{tabular}

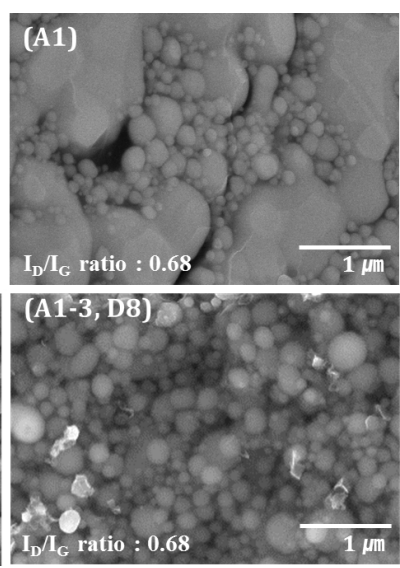

Fig. 6 Raman results and scanning electron microscopy (SEM) micrographs of graphene-coated copper nanoparticle form, based on (A1), (A12 ), and (A1-3, D8) conditions.

condition. Moreover, Raman analysis showed that the copper particles coated with the optimum A1 coating condition (based on the Taguchi method) showed the lowest $I_{\mathrm{D}} / I_{\mathrm{G}}$ ratio, consistent with the Taguchi analysis, minimizing defect conditions. However, the size of the particles grew from $100 \mathrm{~nm}$ to $1 \mu$-scale after the CVD process. The coarsening of parti- 
(a)

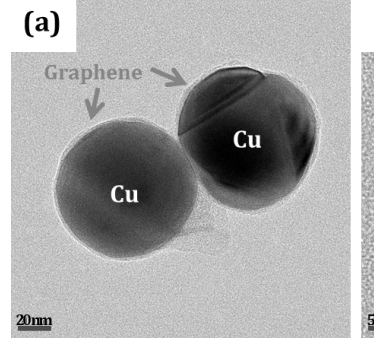

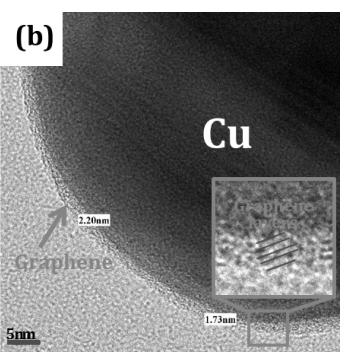

Fig. 7 Transmission electron microscopy TEM micrographs of (a) graphene-coated copper nanoparticle and (b) graphene layers based on (A1-3, D8) condition (the inset is a magnified TEM image of graphene coating layers).

cles may be due to there not being enough PVP solution to coat the surface of $\mathrm{Cu}$ NPs to prevent necking among particles during the CVD process. To overcome this, the amount of PVP solution was increased to 40 and $50 \mathrm{wt} . \%$, to ensure sufficient PVP solution to prevent necking among particles during the CVD process. The microstructures of $\mathrm{Cu}$ NPs in Fig. 6 showed that the shape of copper nanoparticles was maintained with extra PVP solution of 40 (A1-2) and 50 wt.\% (A1-3, D8) after processing at $875^{\circ} \mathrm{C}$. When the polymer was converted to a graphene coating layer, copper nanoparticles maintained their shapes due to this coating layer. These can be expected to prevent oxidation of copper nanoparticles because the coating layer is entirely wrapped around the surface of particles. Moreover, the $I_{\mathrm{D}} / I_{\mathrm{G}}$ ratios for both $\mathrm{A} 1-2$ and A1-3 samples with a graphene coating on the copper particles were measured to be 0.68 .

In particular, $\mathrm{Cu}$ NPs with 50 wt.\% PVP solution (A1-3) (D8) showed a more uniform size distribution of $\mathrm{Cu}$ NPs than that of A1-2. Thus, adding extra PVP solution increased the $I_{\mathrm{D}} / I_{\mathrm{G}}$ ratio slightly, while minimizing necking and preventing coarsening. This slight increase in $I_{\mathrm{D}} / I_{\mathrm{G}}$ ratio agrees with the Taguchi analysis results in Fig. 4. However, Taguchi analysis results focus only on the quality of the graphene and not on necking conditions. Because minimizing necking among $\mathrm{Cu}$ NPs is important for applications, such as of conductive nanoink as much as $I_{\mathrm{D}} / I_{\mathrm{G}}$ ratio for the quality of graphene coating, $\mathrm{Cu}$ NPs with extra 50 wt.\% of PVP solution (A1-3) were found to be the optimum coating condition with a low $I_{\mathrm{D}} / I_{\mathrm{G}}$ ratio.

Additionally, TEM analysis was performed to confirm graphene coating layers onto $\mathrm{Cu}$ NPs to be synthesized based on the optimal conditions as shown in Fig. 7. It has observed that the graphene-coated $\mathrm{Cu}$ NPs had a size of $80 \mathrm{~nm}$ in diameter and the graphene coating surrounded the entire surface of the particles. The thickness of graphene coating onto copper nano-particle was measured to be less than $2.8 \mathrm{~nm}$ and it was confirmed that the graphene coating layer was composed of the five layers (see the inset of TEM image in Fig. 7(b)). This result is consistent with the total thickness of the graphene coating measured in Fig. 7(b), being $1.73 \mathrm{~nm}$, given that a single layer of graphene is known to be $0.37 \mathrm{~nm}^{39}$ )

\section{Conclusions}

The Taguchi method was used to identify optimized process conditions for the fabrication of graphene coatings on $\mathrm{Cu}$

NPs using a minimal number of experiments. Graphene coatings were formed on $\mathrm{Cu}$ NPs using a solid carbon source via CVD. The Taguchi method was used to derive $\mathrm{S} / \mathrm{N}$ ratios from the $I_{\mathrm{D}} / I_{\mathrm{G}}$ ratios of Raman results. The ratio $I_{\mathrm{D}} / I_{\mathrm{G}}$ is related to the defect density.

Based on the Taguchi method, the final optimum coating conditions for graphene coating on $\mathrm{Cu}$ NPs were as follows: a process temperature of $875^{\circ} \mathrm{C}$, a process time of $2 \mathrm{~min}$, a Ar: $\mathrm{H}_{2}$ ratio of 1:1, a PVP molecular weight of $M_{W}=3,500$ (K-12) during the polyol method, and a 30-wt.\% PVP solution with $M_{W}=45,000$ (K-30). However, a significant degree of necking was observed when the optimum conditions were used to coat $\mathrm{Cu}$ NPs with graphene. Next, further experiments were performed to add 40 and $50 \mathrm{wt}$.\% PVP solutions into $\mathrm{Cu}$ NPs. As a result, necking among $\mathrm{Cu}$ NPs was reduced significantly using $50 \mathrm{wt} . \%$ PVP solution while keeping a low $I_{\mathrm{D}} / I_{\mathrm{G}}$ ratio for Raman analysis. Finally, graphene coating on $\mathrm{Cu}$ NPs using $50 \mathrm{wt} \%$ PVP solution showed a uniform distribution of $\mathrm{Cu}$ NPs, successfully preventing coarsening among NPs, with an $I_{\mathrm{D}} / I_{\mathrm{G}}$ ratio of 0.68 . Thus, the Taguchi method was used successfully to identify optimized process conditions for the formation of graphene-coated $\mathrm{Cu}$ NPs.

\section{Acknowledgements}

This work was supported by the National Research Foundation of Korea (NRF) grant, funded by the Korea government (MEST) (No. 2013R1A1A2074605), the Human Resources Development program (No.20154030200680) of the Korea Institute of Energy Technology Evaluation and Planning (KETEP), grant funded by the Korea government Ministry of Trade, Industry and Energy, and the a National Research Foundation of Korea (NRF) grant funded by the Korea government (MEST) (2012R1A2A2A01047189).

\section{REFERENCES}

1) W. Tseng and C.-N. Chen: J. Mater. Sci. 41 (2006) 1213-1219.

2) L. Kwi Jong, J. Byung Ho, K. Tae Hoon and J. Jaewoo: Nanotechnology 17 (2006) 2424.

3) S. Magdassi, A. Bassa, Y. Vinetsky and A. Kamyshny: Chem. Mater. 15 (2003) 2208-2217.

4) S. Magdassi, M. Grouchko and A. Kamyshny: Materials 3 (2010) 4626

5) B.K. Park, D. Kim, S. Jeong, J. Moon and J.S. Kim: Thin Solid Films 515 (2007) 7706-7711.

6) L. Hsien-Hsueh, C. Kan-Sen and H. Kuo-Cheng: Nanotechnology 16 (2005) 2436.

7) X. Xu, X. Luo, H. Zhuang, W. Li and B. Zhang: Mater. Lett. 57 (2003) 3987-3991.

8) M. Cazayous, C. Langlois, T. Oikawa, C. Ricolleau and A. Sacuto: Phys. Rev. B 73 (2006) 113402.

9) J. Kwon, S. Park, Y.-S. Kim and C.S. Lee: J. Nanosci. Nanotechnol. 12 (2012) 1206-1210.

10) J. Her, D. Cho and C.S. Lee: Trans. JIM 54 (2013) 599-602.

11) B.K. Park, S. Jeong, D. Kim, J. Moon, S. Lim and J.S. Kim: J. Colloid Interface Sci. 311 (2007) 417-424.

12) S. Wang, X. Huang, Y. He, H. Huang, Y. Wu, L. Hou, X. Liu, T. Yang, J. Zou and B. Huang: Carbon 50 (2012) 2119-2125.

13) A.L. Norman, K.A. Evagelos and J.S. Wendelin: Nanotechnology 19 (2008) 445201.

14) S. Chen, L. Brown, M. Levendorf, W. Cai, S.-Y. Ju, J. Edgeworth, X. Li, C.W. Magnuson, A. Velamakanni, R.D. Piner, J. Kang, J. Park and R.S. Ruoff: ACS Nano 5 (2011) 1321-1327.

15) B.P. Singh, B.K. Jena, S. Bhattacharjee and L. Besra: Surf. Coat. Tech. 
232 (2013) 475-481.

16) K.I. Bolotin, K.J. Sikes, Z. Jiang, M. Klima, G. Fudenberg, J. Hone, P. Kim and H.L. Stormer: Solid State Commun. 146 (2008) 351-355.

17) A.A. Balandin, S. Ghosh, W. Bao, I. Calizo, D. Teweldebrhan, F. Miao and C.N. Lau: Nano Lett. 8 (2008) 902-907.

18) S. Al-Harthi, M. Elzain, M. Al-Barwani, A. Kora'a, T. Hysen, M. Myint and M. Anantharaman: Nanoscale Res. Lett. 7 (2012) 1-11.

19) H.A. Becerril, J. Mao, Z. Liu, R.M. Stoltenberg, Z. Bao and Y. Chen: ACS Nano 2 (2008) 463-470.

20) F. Banhart, J. Kotakoski and A.V. Krasheninnikov: ACS Nano 5 (2011) 26-41.

21) I.I. Kondrashov, P.S. Rusakov, M.G. Rybin, A.S. Pozharov and E.D. Obraztsova: Journal of Nanoelectronics and Optoelectronics 8 (2013) 83-86.

22) K.S. Kim, Y. Zhao, H. Jang, S.Y. Lee, J.M. Kim, K.S. Kim, J.-H. Ahn, P. Kim, J.-Y. Choi and B.H. Hong: Nature 457 (2009) 706-710.

23) S.-Y. Kwon, C.V. Ciobanu, V. Petrova, V.B. Shenoy, J. Bareño, V. Gambin, I. Petrov and S. Kodambaka: Nano Lett. 9 (2009) 3985-3990.

24) J. Coraux, A.T. N'Diaye, C. Busse and T. Michely: Nano Lett. 8 (2008) 565-570.

25) S. Lee, J. Hong, J.H. Koo, H. Lee, S. Lee, T. Choi, H. Jung, B. Koo, J. Park, H. Kim, Y.-W. Kim and T. Lee: ACS Appl. Mater. Interfaces 5 (2013) 2432-2437.

26) S.-J. Byun, H. Lim, G.-Y. Shin, T.-H. Han, S.H. Oh, J.-H. Ahn, H.C. Choi and T.-W. Lee: The Journal of Physical Chemistry Letters 2 (2011) 493-497.

27) Z. Yan, Z. Peng, Z. Sun, J. Yao, Y. Zhu, Z. Liu, P.M. Ajayan and J.M.
Tour: ACS Nano 5 (2011) 8187-8192.

28) D. Yoon, H. Moon, H. Cheong, J.S. Choi, J.A. Choi and B.H. Park: J. Korean Phys. Soc. 55 (2009) 1299-1303.

29) M. Pimenta, G. Dresselhaus, M.S. Dresselhaus, L. Cancado, A. Jorio and R. Saito: Phys. Chem. Chem. Phys. 9 (2007) 1276-1290.

30) A. Ferrari, J. Meyer, V. Scardaci, C. Casiraghi, M. Lazzeri, F. Mauri, S. Piscanec, D. Jiang, K. Novoselov and S. Roth: Phys. Rev. Lett. 97 (2006) 187401.

31) L. Cancado, A. Reina, J. Kong and M. Dresselhaus: Phys. Rev. B 77 (2008) 245408.

32) S. Santangelo, G. Messina, A. Malara, N. Lisi, T. Dikonimos, A. Capasso, L. Ortolani, V. Morandi and G. Faggio: Diamond Related Materials 41 (2014) 73-78

33) S. Prabhu and B. Vinayagam: Archives of Civil and Mechanical Engineering 11 (2011) 149-170.

34) T.-T. Kao, T.-K. Liu and Y.-W. Tsai: Control \& Automation (ICCA), 11th IEEE International Conference on, IEEE (2014) pp. 590-595.

35) M.-R. Seong, J. Kwon, G.-Y. Lee, D.-K. Kim, Y.-S. Kim and C.S. Lee: Appl. Surf. Sci. 256 (2010) 2332-2336.

36) J. Kwon, S. Park, T.H. Lee, J.-M. Yang and C.S. Lee: Appl. Surf. Sci. 257 (2011) 5115-5120.

37) D. Cho, D. Choi, R.C. Pawar, S. Lee, E.H. Yoon, T. Lee and C.S. Lee: Mater. Chem. Phys. 148 (2014) 859-867.

38) L. Gao, W. Ren, J. Zhao, L.-P. Ma, Z. Chen and H.-M. Cheng: Appl. Phys. Lett. 97 (2010) 183109.

39) W.J. Tseng and C. Chen: J. Mater. Sci. 41 (2006) 1213-1219. 